9. Department of Health and Human Services, Food and Drug Administration. Revised precautionary measures to reduce the possible risks of transmission of Creutzfeldt-Jakob disease (CJD) by blood and blood products. ECRI-Healthcare Environmental Management System 1998;3:5.2.8,3-12.

Elizabeth Ann Bryce, MD

Katerina Dorovoni-Zis, MD

Dianne Trudeau

Margaret Sinclair

Fred J. Roberts, MD

Vancouver Hospital and

Health Sciences Centre

Vancouver, British Columbia

Canada

The authors express their appreciation to $L$. Chan, J. Dunham, J. Fialkow, L. Thain, and $M$. Walker for their assistance in developing the Creutufeldt-Jakob protocol and for their efforts in managing this incident.

\section{Disinfection of Hospital Laundry Using Ozone: Microbiological Evaluation}

\section{To the Editor:}

We investigated a hospital laundry system that uses ozone gas as a disinfection agent. Ozone is a powerful oxidizing agent that has been used as a chemical disinfectant for water treatment in Europe since 1893. ${ }^{1,2}$ The use of ozone has increased in medicine lately due to the number of microorganisms resistant to chlorine. ${ }^{3}$

The process used for washing highly contaminated hospital linen can be summarized as follows: (1) execution of one washing cycle with conventional chemical products (humidification and pre-wash), (2) one washing cycle with ozone (4 $\mathrm{mg} / \mathrm{L}$ ) for 15 minutes, and (3) a softening cycle. Water samples were collected using sterile $20-\mathrm{mL}$ syringes. Pre-wash samples were taken after 2 minutes of agitation without any additives. Post-wash samples were collected similarly, following the final cycle with ozonized water. The samples were evaluated for the most probable number of total coliforms and Escherichia coli using the chromatogenic defined substrate test method (Colilert; Idexx Laboratories, Westbrook, ME).

The most probable numbers ( $\pm \mathrm{SD})$ per $100 \mathrm{~mL}$ of $E$ coli and of total coliforms were $1.3 \pm 0.3 \times 10^{4}$ and $3.74 \pm 1.8 \times 10^{5}$ pre-wash, and were reduced to $0.1 \pm 0.1$ and $1.24 \pm 1.13$, respectively, post-wash (each $P<.0001$ ). Thus, despite intense contamination of the rinsing water, ozone at $4 \mathrm{mg} / \mathrm{L}$ proved able to control the tested microorganisms.

Some studies have shown that many species, ie, E coli, Streptococcus, and Bacillus, can be inactivated by 30 seconds of exposure to an aqueous solution of ozone $(0.2 \mathrm{mg} / \mathrm{L}){ }^{4}$

In the current study, we demonstrated that ozone used in a laundry processing system reduced by five logs the total number of coliforms and $E$ coli present in hospital laundry rinsing water. However, comparative studies testing different conventional disinfectant agents are still necessary to establish the efficacy of ozone as a laundry disinfectant agent.

\section{REFERENCES}

1. Block SS. Disinfection of drinking water, swimmingpool water, and treated sewage effluents. Disinfection, Sterilization, and Preservation. 4th ed. London, UK: Lea \& Fabiger; 1991:713-729.

2. Kawamura $K$, Kaneko $M$, Tsuyoshi $H$, Tagushi K. Microbial indicators for the efficiency of disinfection processes. Water $\mathrm{Sci}$ Tech 1986;10:175-184.

3. Nebel C. Ozone, the process water sterilant. Pharmaceutical Industry 1984;2:16.

4. Gurley B. Ozone: pharmaceutical sterilizant of the future? Journal of Parenteral Science and Technology 1985;39:256-261.

Claudia Catelani Cardoso, DVM João E. Fiorini, PhD

Luciano R. Ferriera, PhD Universidade de Alfenas Alfenas, MG, Brazil

José W.B. Gurjão, ChemEng White Martins Gases Inds. S/A Rio de Janeiro, RJ, Brazil Luiz A. Amaral, PhD UNESP Jaboticabal, SP, Brazil

The authors thank Mr. Nascimento for the technical support; UNIFENAS, White Martins Gases Inds. (Praxair, Inc), for the technical and financial support; and Lavanderia Chanceller for technical assistance.

\section{Impact of Nosocomial Infections on Outcome: Myths and Evidence}

\section{To the Editor:}

In the editorial of the June 1999 issue (1999;20:392-394) of Infection Control and Hospital Epidemiology, regarding the impact of nosocomial infections on outcome, Dr. Jordi Rello concludes that ". . . current evidence is providing a new perspective on the myth that its effect is decisive." In obtaining that conclusion, Dr. Rello cites the publication of Dr. Lilia Soufir et al, in the same issue, regarding catheter-related bloodstream infection. ${ }^{2}$ These articles are good pieces of evidence-based medicine, but I think Dr. Rello missed two points: (1) the impact of catheter-related bloodstream infection is debated, and thus this is a bad example to apply to other nosocomial infections; and (2) not every bacteremia is the same.

It is true that most reported bloodstream infections have been traced to catheter contamination; but, those are the reports from institutions that publish their results, which usually have research units and good nursing standards. Most reports of bacteremia from developing countries involve mainly Klebsiella and Enterobacter, organisms related to more extrinsic infusion contamination than to catheter contamination, ${ }^{3}$ as they are able to grow in parenteral fluids at room temperature. An endemic level of parenteral infusion contamination could exist in many hospitals throughout the world, because highvolume fluid bottles are being used to load burettes of different patients, bottles are left at room temperature for later use after initial manipulation, disposable syringes are used to inject different administrations sets, and vials of drugs designed to be used once are being used for multiple dosing. Some of these lapses in aseptic techniques could exist also for the growing number of patients receiving infusion therapy at home in developed countries. ${ }^{4}$

In our experience culturing inuse infusion fluids in Mexico, extrinsic contamination is common in many hospitals. ${ }^{5,6}$ Because of bias toward accepting publications from researchoriented hospitals, this type of problem has received little attention, and an immense international problem could be underestimated. Klebsiella and Enterobacter bacteremia is a disease of bigger impact on morbidity and mortality, particularly in neonatal units.

Thus, I consider that it is too soon to conclude that the study of the impact of bloodstream infection belongs in the field of mythology. We have observed a dramatic fall in mortality in a hospital after controlling infusate contamination, but have not made a comparative study. ${ }^{6}$ In this process of considering any defendant 
not guilty until proven the opposite beyond statistical significance, it is very dangerous to release on probation suspects of serial killing.

\section{REFERENCES}

1. Rello J. Impact of nosocomial infections on outcome: myths and experience. Infect Control Hosp Epidemiol 1999;20:392-394.

2. Soufir L, Timsit J-F, Mahe C, Carlet J, Regnier B, Chevret S. Attributable morbidity and mortality of catheter-related septicemia in critically ill patients: a matched, riskadjusted, cohort study. Infect Control Hosp Epidemiol 1999;20:396-401.

3. Maki DG. Infections due to infusion therapy. In: Bennett JV, Brachman PS, Sanford JP, eds. Hospital Infections. Boston, MA: Little Brown \& Co; 1992:849-892.

4. Danzig LE, Short LJ, Collins K, Mahoney M, Sepe S, Bland L, et al. Bloodstream infections associated with needleless intravenous infusion system in patients receiving home infusion therapy. JAMA 1995;273:1862-1864.

5. Macías-Hernández AE, Hernández-Ramos I Muñoz-Barrett JM, Vargas-Salado E, Guerrero-Martínez FJ, Medina-Valdovinos $\mathrm{H}$, et al. Pediatric primary gram-negative bacteremia: a possible relationship with infusate contamination. Infect Control Hosp Epidemiol 1996;17:276-280.

6. Macías $\mathrm{AE}, \mathrm{Muñoz} \mathrm{JM}$, Bruckner DA, Galván $\mathrm{A}$, Rodriguez $\mathrm{AB}$, Guerrero $\mathrm{FJ}$, et al Parenteral infusions bacterial contamination in a multi-institutional survey in Mexico: considerations for nosocomial mortality. $\mathrm{Am}$ J Infect Control 1999;27:285-290.

Alejandro E. Macias, MD Facultad de Medicina de León Universidad de Guanjuato, México

\section{The author replies.}

I agree with Macias that my editorial is just a piece in the complex puzzle of understanding the contribution of nosocomial infections (NIs) to outcome. The impact of NIs on outcome has been classically overemphasized by inappropriate estimations of attributable mortality, basically due to a failure to adjust for severity of illness, and this has contributed to the fact that this myth has flown too high. My current belief is that survival in patients with NIs depends above all on the degree of severity at the moment of the diagnosis. ${ }^{1,2}$ In our experience, $^{3}$ most device-related infections are usually caused by pathogens involved in endogenous episodes, and this is a benign process with no significant excess of mortality, if appropriate antibiotic treatment is provided early.

In spite of this, I agree that pathogens acquired exogenously appear to have a poorer prognosis.
This trend was well documented in a study ${ }^{4}$ reporting that mortality directly related to pneumonia caused by Staphylococcus aureus was 20 times greater in methicillin-resistant episodes than in cases of pneumonia caused by methicillin-sensitive strains. What we have learned, and what this author's own experience ${ }^{5,6}$ confirms, is that the epidemiological pattern of exogenous organisms may vary from hospital to hospital, and control measures or therapeutic approaches should be customized to each institution.

In the field of ventilator-associated pneumonia, our group has demonstrated that effective drainage of subglottic secretions ${ }^{7}$ and periodic monitoring of the intracuff pressure ${ }^{8}$ are inexpensive and effective measures in preventing primary endogenous pneumonia. As expected, these measures reduced the period of intubation, but did not modify the ICU survival rate. ${ }^{7}$ In contrast, presence of secondary endogenous or exogenous pathogens will be associated with significant excess mortality, 2,9 and I anticipate that these measures will become ineffective.

All of these pieces of the puzzle are partially recognized but are extremely important in addressing key messages regarding therapy and prevention. Careful handling of the artificial devices (intravenous catheters, intratracheal tubes) is extremely important in preventing NI. The current evidence, however, suggests that these measures should be customized to each institution, as is the case for empirical therapy for nosocomial infections. ${ }^{6}$ In the presence of appropriate infection control measures, mortality is not significantly increased, but the reduction in the rate of endogenous infections by specific interventions will contribute to reducing the economic burden associated with these infections. In contrast, in the presence of exogenous pathogens, the approach should be different and should be targeted to antimicrobial-control programs and increasing handwashing compliance.

\section{REFERENCES}

1. Rello J, Vallés J. Mortality as an outcome in hospital-acquired pneumonia. Infect Control Hosp Epidemiol 1999;20:392-394.

2. Rello J, Rué M, Jubert P, Muses G, Soñora R Vallés J, et al. Survival in patients with nosocomial pneumonia: impact of the severity of illness and the etiologic agent. Crit Care Med 1997;25:1862-1867.
3. Rello J, Vallés J. Hospital-acquired pneumonia in the ICU patient. Semin Respir Crit Care Med 1997;18:133-140.

4. Rello J Torres A Ricart $M$, Vallés J, Gonzalez J, Artigas A, et al. Ventilator-associated pneumonia by Staphylococcus aureus: comparison of methicillin-resistant and methicillin-sensitive episodes. Am J Respir Crit Care Med 1994;150:1545-1549.

5. Rello J. Acinetobacter baumannii infections in the ICU. Chest 1999;115:1226-1229.

6. Rello J, Sa-Borges M, Correa H, Leal SR, Baraibar J. Variations in etiology of ventilator-associated pneumonia across four treatment sites: implications on antimicrobial prescribing practices. Am $J$ Respir Crit Care Med. In press.

7. Vallés J, Artigas A, Rello J, Bonsoms N, Fontanals D, Blanch L, et al. Continuous aspiration of subglottic secretions in preventing ventilator-associated pneumonia. Ann Intern Med 1995;122:179-186.

8. Rello J, Soñora R, Jubert P, Artigas A, Rue M, Vallés J. Pneumonia in intubated patients: role of respiratory airway care. Am J Respir Crit Care Med 1996;154:111-115.

9. Rello J, Jubert P, Vallés J, Artigas A, Rué M, Niederman MS. Evaluation of outcome for intubated patients with pneumonia due to Pseudomonas aeruginosa. Clin Infect Dis 1996;23:973-978.

Jordi Rello, MD, PhD

Hospital Universitari Joan XXIII

Tarragona, Spain

\section{Reasons That Healthcare Workers Decline Influenza Vaccination in a New Zealand Hospital Environment}

\section{To the Editor:}

The Centers for Disease Control and Prevention currently recommends that healthcare workers (HCWs) be vaccinated against influenza each year. ${ }^{1}$ This policy seems to be focused on keeping hospitals operational in the event of a severe influenza epidemic and on preventing transmission to at-risk patients, rather than as a protective mechanism for HCWs (who neither fit into the usual high-risk groups nor show evidence of a greater risk of complications).

Auckland Healthcare has operated influenza vaccination programs for some years. Uptake generally has been poor despite extensive advertising, visiting immunization nurses, drop-in immunization clinics, and a no-charge program.

The occupational groupings of those vaccinated were identified, and nonvaccinated HCWs were identified from payroll lists. Of staff who 